\title{
MOLECULAR DETECTION AND CHARACTERIZATION OF SALMONELLA SPP. ISOLATED FROM FRESH FISHES SOLD IN SELECTED UPAZILA MARKETS OF BANGLADESH
}

\author{
S. K. Seel, S. M. L. Kabir* and M. A. Islam
}

Department of Microbiology and Hygiene, Bangladesh Agricultural University, Mymensingh-2202, Bangladesh

\begin{abstract}
Aquatic environments are the major reservoirs of Salmonella. Therefore, fishery products have been recognized as a major carrier of food-borne organism. Fish is known to harbor bacteria of public health significance. Aquatic environments are known to influence the bacterial loads in the harvested fish. The present work was undertaken for molecular detection and characterization of Salmonella species isolated from fresh fishes sold in different markets of Jamalpur,Tangail, Kishoreganj and Netrokona districts of Bangladesh. The isolates were identified by their morphological, cultural and biochemical characteristics with standard reference organisms, and molecular methods. Out of 20 pangas fish (Pangasius spp.) samples the number of samples found to be positive for Salmonella spp. was 14 (70\%); of 20 koi fish (Anabas spp.) samples this number was 17 (85\%); and of 20 tilapia fish (Oreochromis spp.) samples it was 15 (75\%). All the isolates of Salmonella were confirmed by targeting genus specific histidine transport operon gene. Antimicrobial susceptibility test was performed to know the susceptibility and resistance patterns of the isolates to different antimicrobial agents. Results of antimicrobial susceptibility test shows that $40(86.95 \%)$ isolates were found to be resistant to azithromycin, $42(91.30 \%)$ were resistant to erythromycin. On the other hand all isolates were $100 \%$ susceptible to ciprofloxacin and gentamicin, $38(82.62 \%)$ were susceptible to norfloxacin, $40(86.95 \%)$ were susceptible to streptomycin.
\end{abstract}

Key words: Salmonella spp., Histidine transport operon gene

\section{INTRODUCTION}

With a population of more than 30,000 known species, fish forms the biggest group in the animal kingdom that is used for the production of animal-based foods. About 700 of these species are commercially fished and used for food production. Furthermore, some 100 crustacean and 100 molluscan species (for example mussels, snails and cephalopods) are processed as food for humans in fish industry. However, some fishery product processed in a modern fish industry which is a technologically advanced and complicated industry in line with any other food industry, and with the same risks of product being contaminated with pathogenic organisms. Fish is a popular food item in Bangladeshi food menu. It provides good source of animal protein. This sector contributes $60 \%$ of the daily per capita animal protein intake, $22.60 \%$ of agricultural GDP, and $3.69 \%$ of total GDP. Total fish production in Bangladesh in 2013-14 was 3548 thousand metric tons, of which $83.20 \%$ was from inland fisheries and 16.80\% was from marine fisheries (Bangladesh Economic Review, 2015). Bacteria present in fish are responsible for economic loss due to mortality. Some pathogens are also known to cause zoonotic disease to the handlers and final consumers. Human infection results from contamination of hands and utensils during processing operations especially at evisceration.

Fishes are also known to transmit Salmonella spp., Staphylococcus spp. and Aeromonas spp. which are the causal agent of human food borne infection and intoxication (Gold and Salit, 1993). Bacteria found in fish are classified into non-indigenous and indigenous bacteria. The non-indigenous bacteria include Clostridium botulinum, Listeria monocytogenes, Staphylococcus aureus, Salmonella spp., Shigella spp. and E. coli. On the other hand, indigenous bacteria include Vibrio spp, Staphylococcus aureus, Salmonella, Shigella, Aeromonas, Yersenia and Pseudomonas (Clucas and Ward, 1996). Bacillus, Proteus, Pseudomonas, Klebsiella, Streptococcus, Salmonella, Staphylococcus, Micrococcus, Serratia and Escherichia are found in the skin and intestine of fish (Tiamiyu et al., 2011). The bacteria from the surface of fresh water fish known to carry Acineto bactercalcoaceticusae, A hydrophila, A. bestiarum, A. caviae, A. jandaei, A. schubertii, A. veronii, Entero bacteraerogenes, E. coli and Flavobacterium (Zmyslowska et al., 2001). The bacteria present in gill include $E$. coli, Citrobacter spp., Enteriobacter spp. and Klebsiella spp.

*Corresponding e-mail address: 1kabir79@yahoo.com

Copyright $(C) 2016$ Bangladesh Society for Veterinary Medicine

All rights reserved 0388/2016 


\section{S. K. Seel and others}

The Microbiology of skin and gastro intestinal tract of fish has been studied by many researchers. Fish can be spoiled from both outer surface and inner surfaces. After fish is being caught the immune system collapses with its eventual death, bacteria can proliferate freely on the skin surface and the stomach. The walls of intestine do break down sufficiently for bacteria to move into the flesh through the muscle fiber (Kaneko, 1971). The main objectives of the present research work were isolation and identification of bacteria from fish samples and antimicrobial susceptibility patterns of isolated bacteria with the detection of Salmonella spp. based on histidine transport operon gene PCR.

\section{MATERIALS AND METHODS}

\section{Sample collection}

A total of 60 fresh fish samples (20 pangas fish, Pangasius spp.; 20 koi fish, Anabas spp. and 20 tilapia fish, Oreochromis spp.) were collected from different upazila markets of Jamalpur, Tangail, Kishoreganj and Netrokona districts of Bangladesh. The samples were collected from July 2015 to December 2015 and investigation was carried out following collection. The collected milk samples were immediately transported on ice to the Microbiology Laboratory at the Department of Microbiology and Hygiene of BAU and District Veterinary Hospital, Sirajgonj for bacteriological analysis.

\section{Isolation and identification of Salmonella spp.}

$10 \mathrm{gm}$ of sample were taken from skin, gills and intestine by cutting with a sterile scalpel. Then the samples were grinded by using mortar and pestle. Then grinded fish samples were performed 10 fold dilution using $0.1 \%$ peptone water and diluted samples were spread onto XLD agar (HiMedia®, India) incubated at $37^{\circ} \mathrm{C}$ for overnight. Then the presumptive colonies of Salmonella spp. were sub-cultured onto SS agar and XLD agar to get pure culture. These isolates were preserved for further bacterial identification. The isolates were identified as Salmonella spp. on the basis of Gram staining, colony morphology on XLD agar (HiMedia®, India), SS agar, biochemical characterization of the isolates (using sugar fermentation test, indole and MR-VP test). Further the isolates were detected by histidine transport operon gene based PCR.

\section{Bacterial Genomic DNA extraction}

DNA template was prepared by boiling method briefly $250 \mu \mathrm{l}$ distilled water was taken into eppendorf tube and a pure bacterial colony was picked up and mixed with the distilled water. The tubes then transferred to boiling water and boiled for 10 minutes then immediately transferred to ice for cold shock about 10 minutes and then centrifuged at $10000 \mathrm{rpm}$ for 10 minutes. Supernatant were collected and used as DNA template during PCR.

\section{Identification of Salmonella spp. by PCR}

PCR reaction was performed to detect Salmonella spp. by histidine transport operon gene based PCR. Two different primers pairs were used for this purpose, histidine transport operon gene (F 5'ACTGGCGTTATCCCTTTCTCTGGT-3' and R 5' ATGTTGTCCTGCCCCTGGTAAGAG-3') according to the methods described by Cohen et al. (1993). Each $20 \mu 1$ reaction mixture consists of $3 \mu 1$ genomic DNA, $10 \mu 1$ PCR master mixtures (Promega, USA), and $1 \mu 1$ of each of the two primers with the final volume adjusted to 20 $\mu 1$ with $5 \mu 1$ of nuclease free water. Amplification was done by initial denaturation at $95^{\circ} \mathrm{C}$ for 5 minutes, followed by denaturation at $94^{\circ} \mathrm{C}$ for $30 \mathrm{sec}$, annealing temperature of primers was $56^{\circ} \mathrm{C}$ for $30 \mathrm{sec}$ and extension at $72^{\circ} \mathrm{C}$ for $45 \mathrm{sec}$. The final extension was conducted at $72^{\circ} \mathrm{C}$ for 5 minutes. The total reaction was performed at 30 cycles. The amplified PCR products were resolved by electrophoresis in $2 \%$ agarose gel at $100 \mathrm{v}$ for 30 minutes, stained with ethidium bromide and finally visualized under UV trans-illuminator.

\section{Antibiotic sensitivity test}

All isolates separated from pangus fish (Pangasius spp.), koi fish (Anabas spp.) and tilapia fish (Oreochromis spp.) were tested for antimicrobial drug susceptibility against antimicrobial agents by disc diffusion method according to the guidelines of Clinical and Laboratory Standard Institute (CLSI, 2012). Sensitivity pattern of the isolates were determined against ciprofloxacin, azithromycin, gentamicin, amoxycillin, streptomycin, erythromycin, tetracycline and norfloxacin. Antimicrobial testing results were recorded as sensitive, intermediate sensitive and resistant according to zone diameter interpretative standards provided by CLSI (2012). 


\section{RESULTS AND DISCUSSION}

A total of 60 samples were collected for the isolation of bacteria from fresh fishes (pangas fish, Pangasius spp.; koi fish, Anabas spp. and tilapia fish, Oreochromis spp.) sold from different upazilla markets of Bangladesh. Out of 20 koi fish (Anabas spp.) samples $85 \%(\mathrm{n}=17)$ were contaminated with Salmonella spp., out of 20 tilapia fish (Oreochromis spp.) samples 75\% (n=15) were contaminated with Salmonella spp and out of 20 pangas fish (Pangasius spp.) samples $70 \%(\mathrm{n}=14)$ were contaminated with Salmonella spp. In xylose-lysine deoxycholate (XLD) agar the Salmonella spp. produced blackish centered colony (Figure 1). In salmonellashigella (SS) agar the Salmonella spp. produced small, round smooth colony with black centre (Figure 2). In Gram's staining, organism revealed as pink colored short rod shaped bacteria arranged in single or paired (Figure 3). These isolates were positive for catalase and coagulase test. In catalase test; Hydrogen peroxide was broken-down into water and oxygen. Production of oxygen was indicated by bubble formation, whereas the negative control did not produce any bubble.

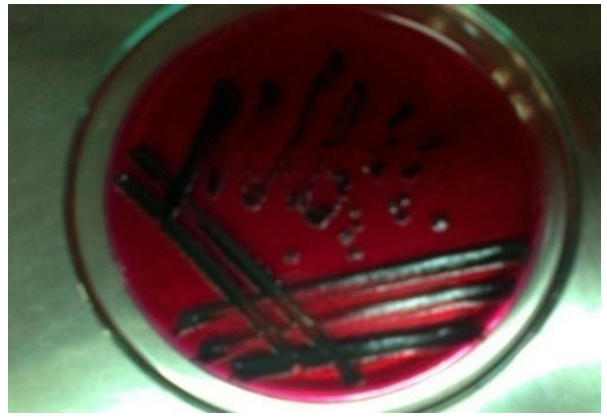

Figure 1. Salmonella spp. produces round black center colony in XLD agar media.

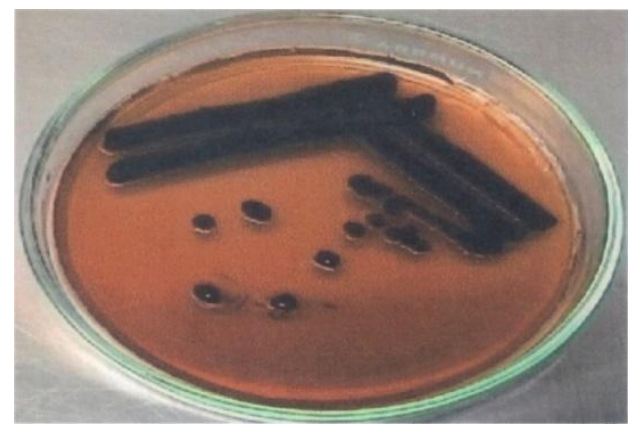

Figure 2. Translucent black smooth, small round colonies of Salmonella spp. on SS agar media.

Molecular detection of Salmonella spp. was performed by histidine transport operon gene based PCR method. Specific 496 bp fragment of targeted histidine transport operon gene was amplified successfully (Figure 4). Each genus was subjected to antimicrobial susceptibility test by disc diffusion method against 8 most commonly used antimicrobial agents. $40(86.95 \%)$ isolates were found to be resistant to azithromycin, $40(91.30 \%)$ were resistant to erythromycin. Furthermore, all isolates were susceptible to ciprofloxacin and gentamicin, $38(82.62 \%)$ were susceptible to norfloxacin, $40(86.95 \%)$ were susceptible to streptomycin (Figure 5)

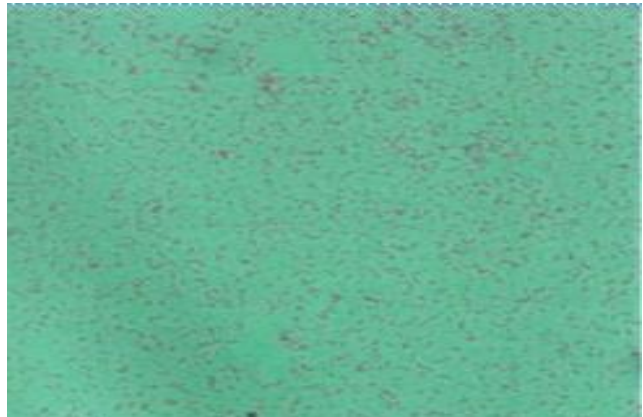

Figure 3. Gram-negative very short plump' rods of Salmonella spp. (100X).

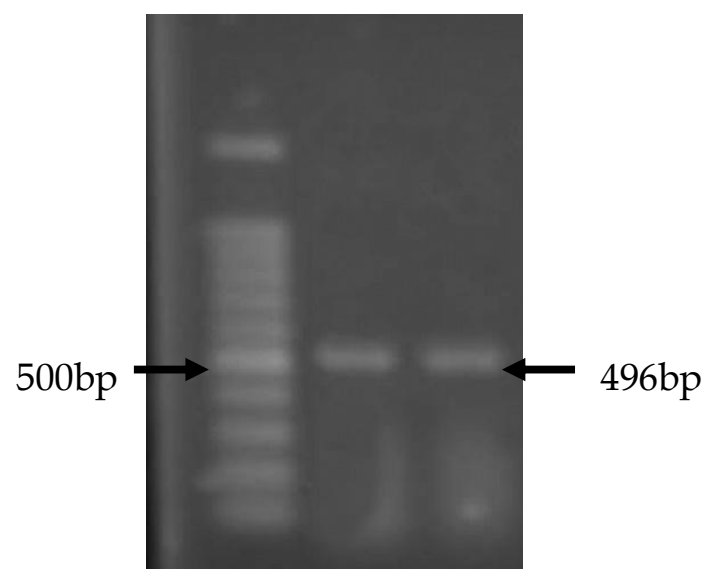

Figure 4: Detection of Salmonella spp. by histidine transport operon gene based PCR. Lane 1:100bp DNA marker, lane 2, 3: DNA of Salmonella spp. 


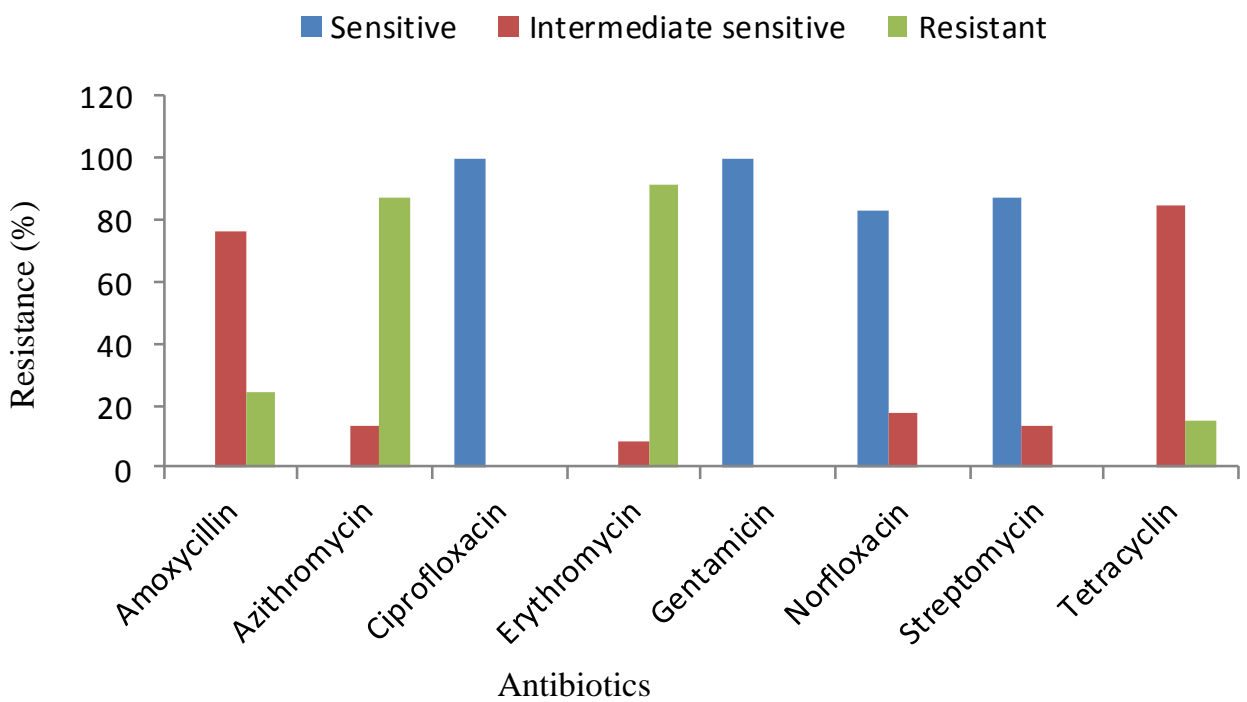

Figure 5. Antibiotic resistance patterns of Salmonella spp. against commonly used antibiotics in Bangladesh

The present study was designed for identification and characterization of Salmonella spp. from fresh fish sample. Total 60 samples (20 pangas fish, Pangasius spp.; 20 koi fish, Anabas spp. and 20 tilapia fish, Oreochromis spp.) were collected and analyzed. Out of 20 pangasius fish samples 14 samples were revealed the positive result for Salmonella spp.; of 20 koi fish samples 17 samples were revealed the positive result for Salmonella spp.; of 20 tilapia fish samples, 15 samples were revealed the positive result for Salmonella spp. Salmonella spp. were identified and were confirmed by cultural examination, morphological studies, staining characters and biochemical tests and finally PCR were performed for the amplification of histidine transport operon gene of isolated bacteria.

Salmonellosis is still a global challenge to public health. Salmonellosis is an important food borne infective disease worldwide, occurring mostly as sporadic cases in families or as outbreaks. Now a days Fish and fish products are the important source of Salmonella spp. Salmonella spp. is a recognized human pathogen and its waterborne transmission has been well documented (Cabral, 2010). Poultry and poultry products have been the most commonly implicated foods to cause infection in human. Although meat and meat products, milk and milk products, and water have also been associated with large outbreaks of salmonellosis (Inatsu et al., 2013).

Results of antimicrobial susceptibility test showed that most of the isolates of Salmonella were susceptible to ciprofloxacin (100\%), gentamicin (100\%), streptomycin $(86.95 \%)$ and norfloxacin $(82.62 \%)$. Most of the isolates were intermediate susceptible to tetracycline $(84.78 \%)$ and amoxycillin $(76.08 \%)$ and resistant to erythromycin $(91.30 \%)$ and azithromycin (86.95\%). These findings are slightly correlated to Swati et al. (2015) and Mahmuda et al. (2010).

\section{CONCLUSION}

Fish is an important source of animal protein for human diet. Fish are susceptible to a wide variety of bacterial pathogen. Many of these bacteria are capable of causing human infection and intoxication. The microbiological hazard of Salmonella contamination of fish and fish products during storage and improper handling or cooking of fish can lead to human food-borne illness. Hence, there is need to monitor the contamination levels of Salmonella as well as other zoonotic pathogens throughout the year to safeguard public health. The present work was undertaken for molecular detection and characterization of Salmonella species isolated from fresh fishes sold in different markets of Bangladesh. Out of 60 samples of pangus fish (Pangasius spp.), koi fish (Anabas spp.) and tilapia fish (Oreochromis spp.) of 20 each 14 (70\%), $17(85 \%)$ and $15(75 \%)$ samples were positive for Salmonella respectively. The isolates were identified by their morphological, cultural properties, biochemical 
characteristics with standard reference organisms and molecular methods. All the isolates of Salmonella were confirmed by targeting genus specific histidine transport operon gene. Results of antimicrobial susceptibility test showed that most of the isolates of Salmonella were susceptible to ciprofloxacin (100\%), gentamicin (100\%), streptomycin $(86.95 \%)$ and norfloxacin $(82.62 \%)$. Most of the isolates were intermediate susceptible to tetracycline $(84.78 \%)$ and amoxycillin $(76.08 \%)$ and resistant to erythromycin $(91.30 \%)$ and azithromycin $(86.95 \%)$. Resistant pattern against broad spectrum antibiotic (e.g., erythromycin and azithromycin) depicts an alarming situation which needs special consideration.

\section{ACKNOWLEDGEMENTS}

We would like to thank sincerely the Food and Agriculture Organization of the United Nations (FAO) for giving financial and logistic support.

\section{REFERENCES}

1. Bangladesh Economic Review (2015). Ministry of Finance, The Peoples' Republic of Bangladesh PP 91.

2. Cabral JPS (2010). Water microbiology. Bacterial pathogens and water. International Journal of Environmental Research and Public Health 7: 3657-703.

3. Clinical and Labratory Standards Institute (CLSI, formerly NCCLS) (2012). Performance standards for antimicrobial susceptibility testing. $22^{\text {nd }}$ Informational Supplement document MI00-S22: 32: 3. Wayne, PennsysIvania pp. 34-53.

4. Clucas IJ and Ward AR (1996). Post-harvest fisheries development: A guide to handling, preservation, processing and quality. Charthan Maritime, Kent ME4 4TB, United Kingdom. pp. 113-116.

5. Gold WL and Salit IE (19930. Aeromonas hydrophila infections of the skin and soft-tissue: Report of 11 cases and review. Clinical Infectious Diseases 1: 69-74.

6. InatsuY, HosotaniY, Kawasaki S and Ananchaipattana C (2013). Detection and characterization of Salmonella spp. in various kinds of food sold in Bangkok, Thailand, International Symposium on Agri-Foods for Health and Wealth August 5-8, 2013, Golden Tulip Sovereign Hotel, Bangkok, Thailand.

7. Kaneko S (1971). Microbiological study of fresh fish new food industries. Journal of Microbiology and Biotechnology Research 1: 176-180.

8. Mahmuda B, Tweb AA and Monika D (2010). Comparative mirobiological assessment of five types of selected fishes collected from two different markets. Advances in Biological Research 4: 259-265.

9. Swati S, Kshirsagar DP, Brahmbhatt MN, Nayak JB and Chatur YA (2015). Isolation and characterization of Salmonella spp. from buffalo meat samples. Buffalo Bulletin 34, Department of Veterinary Public Health and Epidemiology, Veterinary College, Anand Agricultural University (AAU), Anand, India.

10. Tiamiyu AM, Obuko B and Emikpe A (2011). Isolation and identification of aerobic bacterial Oreochromis niloticus from lbadan, Southwest Nigeria. Journal of Applied Sciences Research 7: 1047-1051.

11. Zmyslowka, Lewandowska D and Guziur J (2001). Sanitary and bacteriological studies of water and European Catfish (Silurus glanis) during wintering. Archives of Polish Fisheries 10: 177-186. 